Mirai. Estudios Japoneses

ISSN-e: $2531-145 X$

http://dx.doi.org/10.5209/mira.67401

\title{
Una lectura feminista de La llama de Uemura Shōen
}

\author{
Ana Galán Sanz ${ }^{1}$
}

Resumen. Uemura Shōen (1875-1949) fue una reconocida artista japonesa especialista en bijinga ${ }^{2}$. Su dedicación al arte se refleja en sus pinturas y en sus memorias. Aquí se presenta a esta artista por medio de un análisis completo de La llama, pintura de 1918 que encarna el espíritu vengativo de la dama Rokujō.

El objetivo que persigo es aportar una re-lectura de esta obra, y pretendo demostrar que ha sido malentendida por numerosos críticos como una simple representación de los celos. Sin embargo, escuchando a la artista, se entiende cómo verdaderamente su obra dista del imaginario artístico patriarcal que define esta feminidad desviada. Así, se demostrará cómo Shōen emplea esta pintura como un lenguaje reivindicativo donde expresa su propia mirada, con la que desarticula los estereotipos impuestos por el imaginario androcéntrico y muestra su compromiso feminista a través de su arte.

Palabras clave: Uemura Shōen; bijinga; arte feminista; mujeres artistas; Japón

\section{[en] A feminist reading of Flame by Uemura Shōen}

Abstract. Uemura Shōen (1875-1949) was a renowned Japanese artist specialist in bijinga. Her dedication to art is reflected in her paintings and in her memoirs. This artist is presented here through a complete analysis of Flame, a painting from 1918 that represents the vengeful spirit of Lady Rokujō.

My objective here is to provide a new reading of this work because the figure has been misunderstood by numerous art critics as a simple representation of jealousy. However, listening to the artist, it is understood that in fact her work is far from the patriarchal artistic imaginary that defines this deviant femininity. In this way, it will be demonstrated how Shōen uses this painting as a political language where she expresses her own gaze, with which she dismantles the stereotypes imposed by the androcentric imaginary and shows her feminist commitment through her art.

Keywords: Uemura Shōen; bijinga; feminist art; women artists; Japan

Sumario. 1. Introducción y metodología; 2. ¿Quién es Uemura Shōen?; 3. La llama: un estudio; 3.1. Buscando la inspiración en el nō: Aoi no Ue; 3.2. El espíritu vivo de Rokujō; 3.3. Algún detalle técnico de La llama; 3.4. La verdadera venganza de Uemura Shōen; 4. Conclusiones.

Cómo citar: Galán Sanz, A. Una lectura feminista de La llama de Uemura Shōen, en Mirai. Estudios Japoneses, 4, 2020, 129-142.

\section{Introducción y metodología}

A pesar de que la presencia de mujeres pintoras ha sido constante dentro del universo artístico japonés, las artistas han tenido más limitaciones a la hora de triunfar que sus colegas varones. Sin embargo, durante el periodo Edo (16031868), una época de renacimiento cultural propiciada por la estabilidad política y económica del país, aparecen ya numerosas mujeres que rompen con el rol impuesto de servir únicamente a su hogar y deciden dedicarse a alguna disciplina artística ${ }^{3}$. Aunque la llegada de la era Meiji (1868-1912) trae consigo la disolución del sistema feudal y se declara la igualdad de toda la población japonesa, prevalece la inferioridad de las mujeres ${ }^{4}$ con la imposición de la ideología de la "buena esposa y sabia madre". Este discurso, que inculca una identidad nacional a las mujeres, tiene como objetivo establecer unos roles de género determinados en el Japón moderno ${ }^{5}$. No obstante, y a pesar del abuso y discriminación que muchas seguían sufriendo, las mujeres japonesas iban demostrando poco a poco su capacidad

Ana Galán Sanz. Doctoranda en el Programa de Estudios Interdisciplinares de Género. Universidad Autónoma de Madrid. Correo electrónico: anavictoria.galan@estudiante.uam.es

VV.AA. (1990): 534; bijinga (美人画) o representación de mujeres bellas (bijin) constituye un género dentro de la tradición del nihonga o pintura japonesa. Tiene su origen en las estampas ukiyo-e. Sin embargo, el problema de la belleza externa o interna es a menudo un tema de discusión.

Fister, P. (1988): 9.

Ibid.: 14.

Iwahori Y. (1999): 396. 
para mantenerse por ellas mismas y ser independientes ${ }^{6}$. Esto último se refleja, por ejemplo, en el mundo artístico, pues es en el periodo Meiji cuando comienza a aceptarse y reconocerse a mujeres como artistas profesionales, y son numerosas las pintoras que presentan sus trabajos en exposiciones nacionales e internacionales, se forman en escuelas especializadas y son admitidas en diversas asociaciones artísticas?.

En este artículo se presentará a una de estas artistas que triunfó, la pintora japonesa Uemura Shōen (1875-1949), a través del análisis de una de sus obras más célebres, La llama, en japonés [焰] Honoo [fig. 1], elaborada en 1918. Sin embargo, aquí no se realizará una mera introducción a la figura de esta artista, sino que este cuadro será analizado desde varios campos de estudio. De esta manera, la metodología que se aplicará en este artículo es la siguiente. Por un lado, se trabajará con la traducción del japonés al castellano de las memorias de Shōen. Este texto resulta de gran utilidad a la hora de profundizar no solo en el desarrollo artístico de esta pintora, sino también para comprender las opiniones que ella misma tenía acerca de la sociedad y la cultura que la rodeaba. A partir de la escritura de sus memorias, Shōen toma el control y cuenta su propia historia en lugar de dejar que narrativas escritas por otros se asuman. Por otro lado, a fin de desarrollar este empoderamiento que la artista manifiesta en sus palabras, resulta esencial recurrir a su obra artística y realizar una lectura completa de sus pinturas bajo una nueva mirada; no se elaborará únicamente un estudio artístico de las figuras sino también un análisis más social donde se introduzca la perspectiva de género. Además, en la aproximación a la pintura La llama, se comentará, por una parte, la inspiración literaria de la figura protagonista, el fantasma Rokujo $\bar{o}^{8}$, pero también se realizará un análisis de la técnica artística que aquí se emplea o del significado que Shōen inculca a esta pintura. Así, para poder llevar a cabo este último punto, se recurrirá a una fuente primordial, las palabras de Shōen extraídas de sus memorias y que son un lenguaje que la artista emplea como un campo de batalla sobre el contenido y el significado de su propio arte.

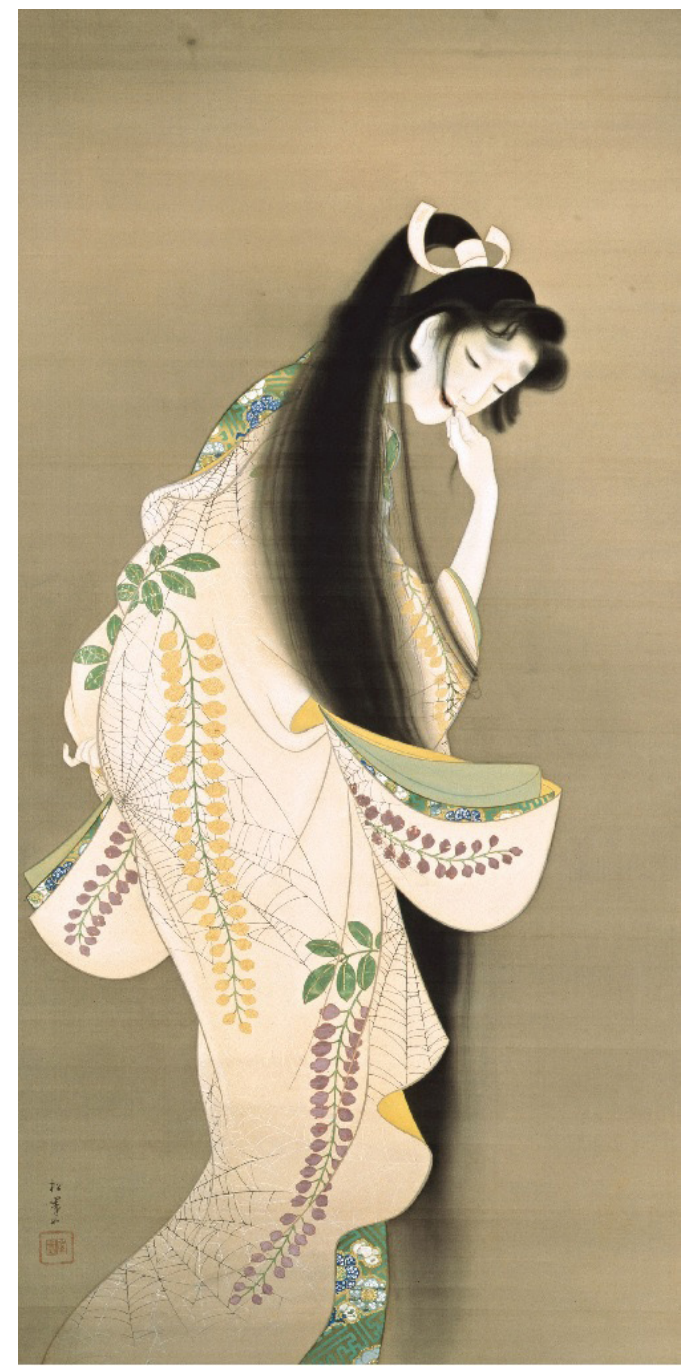

Fig. 1. Uemura Shōen. La llama (焔, Honoo), 1918.

Pintura sobre seda en rollo vertical, 190,9 x $91,8 \mathrm{~cm}$. Tokyo National Museum.

Hirota, M. (1999): 206

Fister, P. (1988): 15.

VV.AA. (1972): vol. 20: 565: Rokujō no Miyasudokoro (六条御息所) fue la viuda del príncipe Zenbō (前坊) y amante de Hikaru Genji (光源氏), protagonista de la novela Genji monogatari (『源氏物語』), la obra maestra de la literatura japonesa elaborada a comienzos del siglo XI y cuya autoría se ha atribuido tradicionalmente a Murasaki Shikibu. En uno de los capítulos de esta novela se transforma en un espíritu vivo y, promovida por sus celos, aniquila el alma de la dama Aoi. 


\section{2. ¿Quién es Uemura Shōen?}

Resulta imprescindible presentar a Shōen con una breve nota biográfica sobre su persona para a continuación poder profundizar en su obra y su visión sobre el hecho de ser mujer. Uemura Shōen (Kioto, 1875 - Nara, 1949), cuyo nombre real era Uemura Tsune, fue, tal y como se ha mencionado previamente, una pintora japonesa nacida en la ciudad de Kioto. Huérfana de padre, que falleció dos meses antes de su nacimiento, fue su madre quien la crio y apoyó en todo momento en su deseo de dedicarse profesionalmente a la pintura, un mundo que en el Japón de aquellos años era prácticamente monopolio masculino. Nakako, su madre, no volvió a casarse y logró a base de empeño y un gran esfuerzo los recursos suficientes con los que mantener a sus dos hijas. De este modo, se convirtió en un modelo de madre que Shōen plasmaría en sus obras por medio de una simbología que evoca la belleza tradicional de Japón ${ }^{9}$, concretamente la de finales del periodo Edo. Shōen, que desde niña mostraba un gran interés hacia la pintura, se matriculó en la Escuela de Pintura de la Prefectura de Kioto. A pesar de que algunos de sus familiares la criticaron por elegir la carrera artística y no otras disciplinas consideradas más "femeninas", como el arte de la ceremonia del té o la costura, su madre se convirtió en su pilar de apoyo. En esta escuela de pintura fue donde conoció a su primer maestro Suzuki Shōnen (1849-1918), quien la bautizó como Shōen ${ }^{10} \mathrm{y}$, en el año 1890, cuando la artista contaba con apenas quince años, elaboró su primera obra expuesta, Bellezas de las cuatro estaciones (四季美人図, Shiki bijin-zu) [fig. 2]. La pintura fue adquirida ese mismo año por el príncipe británico Arturo de Connaught (1850-1942), hijo de la reina Victoria, que en esos momentos se encontraba de visita por Japón. Este hecho tuvo cierta relevancia en el Kioto de finales del siglo XIX y fue sin duda un impulso a la carrera profesional de Shōen ${ }^{11}$. Tras varios años bajo la tutela del maestro Shōnen, decidió, con el permiso de este último, acudir a los talleres de los artistas Kōno Bairei (1844-1895) y Takeuchi Seihō (1864-1942) para así poder formarse en lo que ella realmente deseaba, la representación de figuras humanas. Gracias a la influencia de estas tres figuras, Shōnen, Bairei y Seihō, Shōen alcanzó un estilo de pintura muy particular en el género bijinga o representación de mujeres bellas.

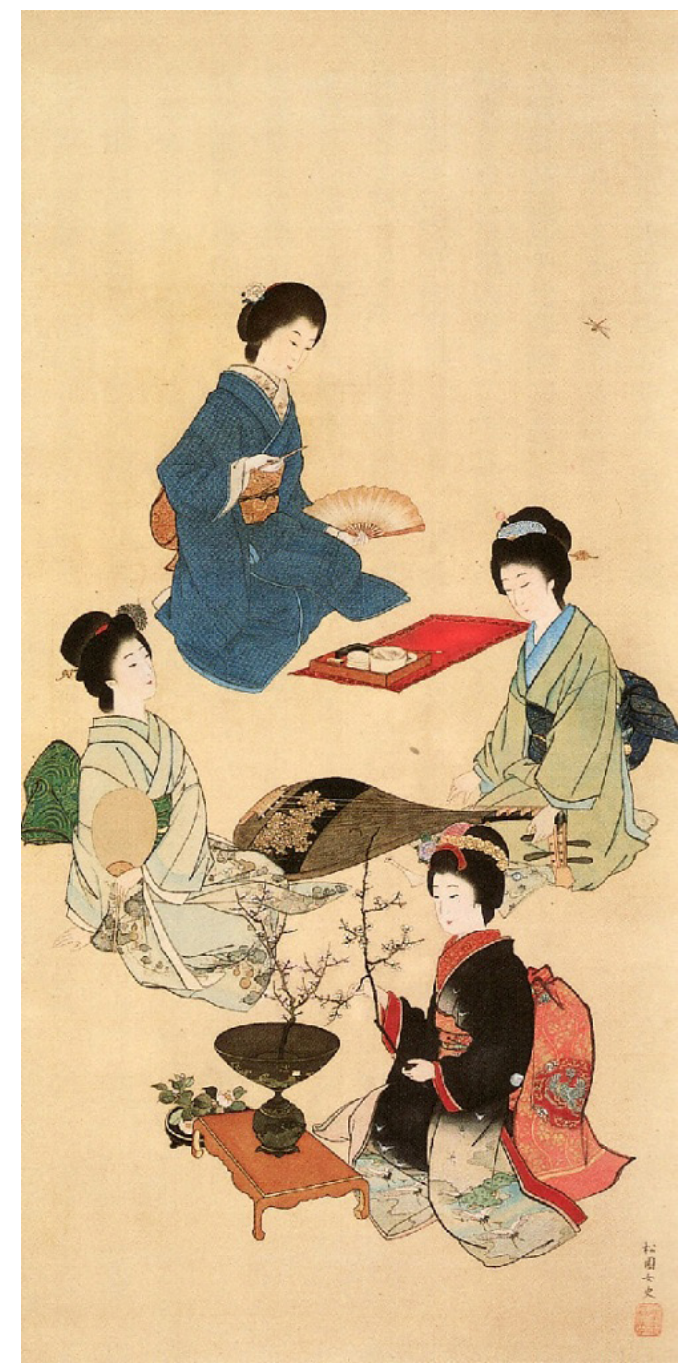

Fig. 2. Uemura Shōen. Bellezas de las Cuatro Estaciones (四季美人図, Shiki bijin-zu) 1892. Pintura sobre seda en rollo vertical, 130,5 x 56,7 cm. Hikaru Memorial Museum. 
A pesar de la dificultad de ser valorada por la mayoría de sus compañeros varones, pronto su trabajo fue reconocido y comenzó a recibir premios por sus trabajos expuestos tanto en Japón como en el resto de exhibiciones internacionales que tenían lugar en Europa y Norteamérica. Así, Shōen participó a lo largo de su vida en cinco exposiciones universales y más de diez internacionales. Sin embargo, este camino no fue sencillo y eran muchos los que se quedaban en una lectura superficial de sus obras y la criticaban por un estilo excesivamente tradicional y poco innovador comparado con las formas artísticas consideradas modernas que tenían un gran éxito en Tokio, la capital, tal y como se analizará más adelante ${ }^{12}$. Pero Shōen también encontraba obstáculos dentro de su vida privada, pues fue madre soltera de un niño, quien más tarde sería también pintor, Uemura Shōkō (1902-2001), hijo del primer maestro de la artista, Suzuki Shōnen. A consecuencia de esto, fue atacada por numerosas familias que prohibieron a sus hijas acudir al taller de Shōen a formarse por no considerar a la artista como un modelo apropiado a seguir ${ }^{13}$. Tras estos duros momentos, Shōen no se dio por vencida y siguió pintando hasta el último día de su vida. Prueba de ello son sus grandes obras maestras, como Flores de la Vida (人生の花, Jinsei no hana) [fig. 3], Larga velada (長夜, Nagayo) [fig. 4], Cesto de Flores (花がたみ, Hanagatami), Amapola (楊貴妃, Yōkihi) [fig. 5] o Danza introductoria (序の舞, Jō no mai) [fig. 6]. Su gran dedicación al arte no pasó desapercibida en las esferas artísticas y participó en varias ediciones de la afamada Bunten ${ }^{14}$, la Exhibición del Ministerio de Educación y Arte $^{15}$. No obstante, Shōen, de carácter reservado e introvertido, se independizó de ciertas asociaciones de pintura de estilo japonés que surgían en Kioto y cesó su participación en varias exposiciones de arte ${ }^{16}$. A pesar de ello, en 1924 se convirtió en la primera mujer miembro del jurado de la Teiten ${ }^{17}$, la exhibición gubernamental que sucedió al Bunten ${ }^{18}$.

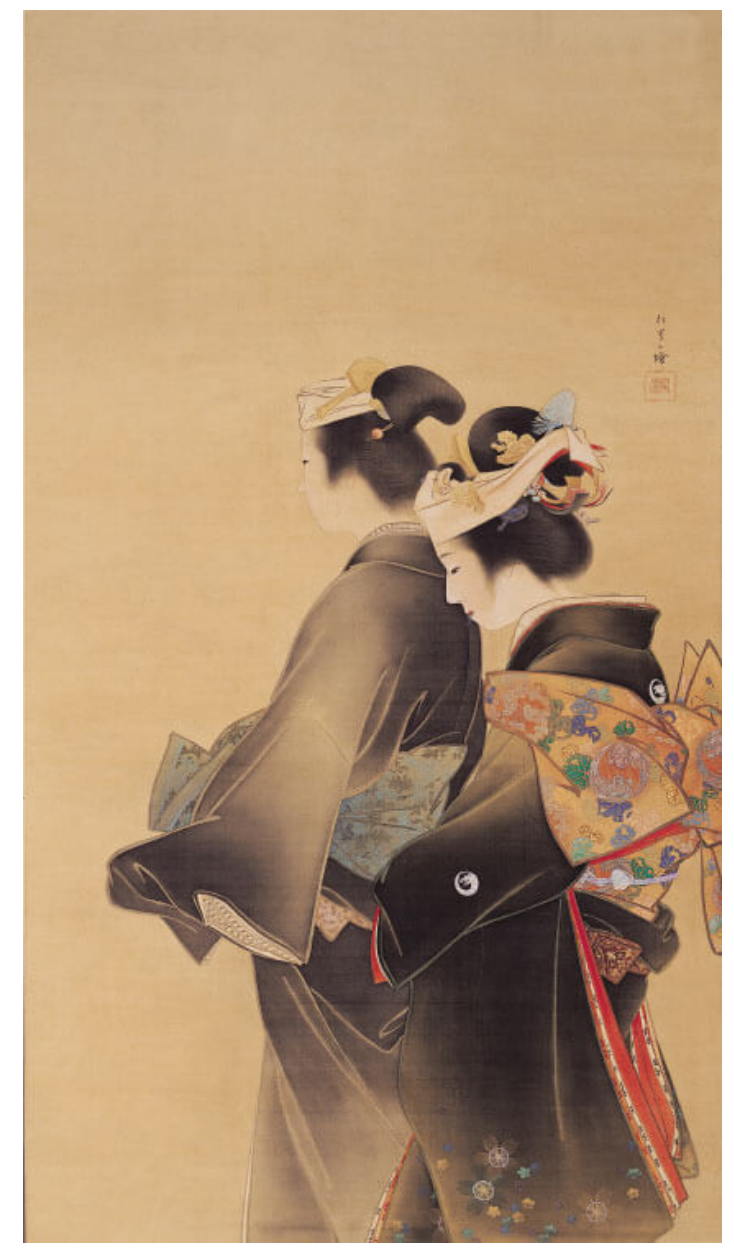

Fig. 3. Uemura Shōen. Flores de la vida (人生の花, Jinsei no hana), 1899.

Pintura sobre seda en rollo vertical, 161 x 86,5 cm. Kyoto Municipal Museum of Art.

12 Tanaka, K. (2007): 34, 35.

13 Yamada, N. / Merrit, H. (1993): 12.

14 VV.AA. (1990): 568; Bunten es la abreviatura de la Exhibición del Ministerio de Educación y Arte o Monbushō bijutsu tenrankai (文部省美術展 覧会). Continuando el ejemplo del Salón en Francia, este Ministerio patrocinó esta exhibición competitiva entre los nuevos trabajos desde el año 1907 hasta 1918. Dentro del Bunten, existían tres secciones diferenciadas: la dedicada a la pintura de estilo japonés o nihonga, la de estilo occidental o yōga, y la escultura. Previamente a su exhibición, las obras debían ser juzgadas con el fin de seleccionar solo aquellas que pudieran enseñarse al público. En el Bunten también se realizaba una entrega de premios a los mejores trabajos de cada año.

15 Morioka M. (1990): 68.

16 Yamada, N./ Merrit H. (1993): 13, 14.

17 VV.AA. (1990): 442; Teiten es la abreviatura de la Exhibición del Instituto Imperial de Bellas Artes o Teikoku bijutsu-in tenrankai (帝国美術院展 覧会). Esta, que sucedió al famoso Bunten, fue patrocinada por el Instituto Imperial de Bellas Artes y se celebró desde el año 1919 hasta el 1934. Esta exhibición añade una nueva sección de artesanías o kōgei, además de las tres que ya habían aparecido en el Bunten.

18 Yamada, N. / Merrit H. (1993): 13, 14. 


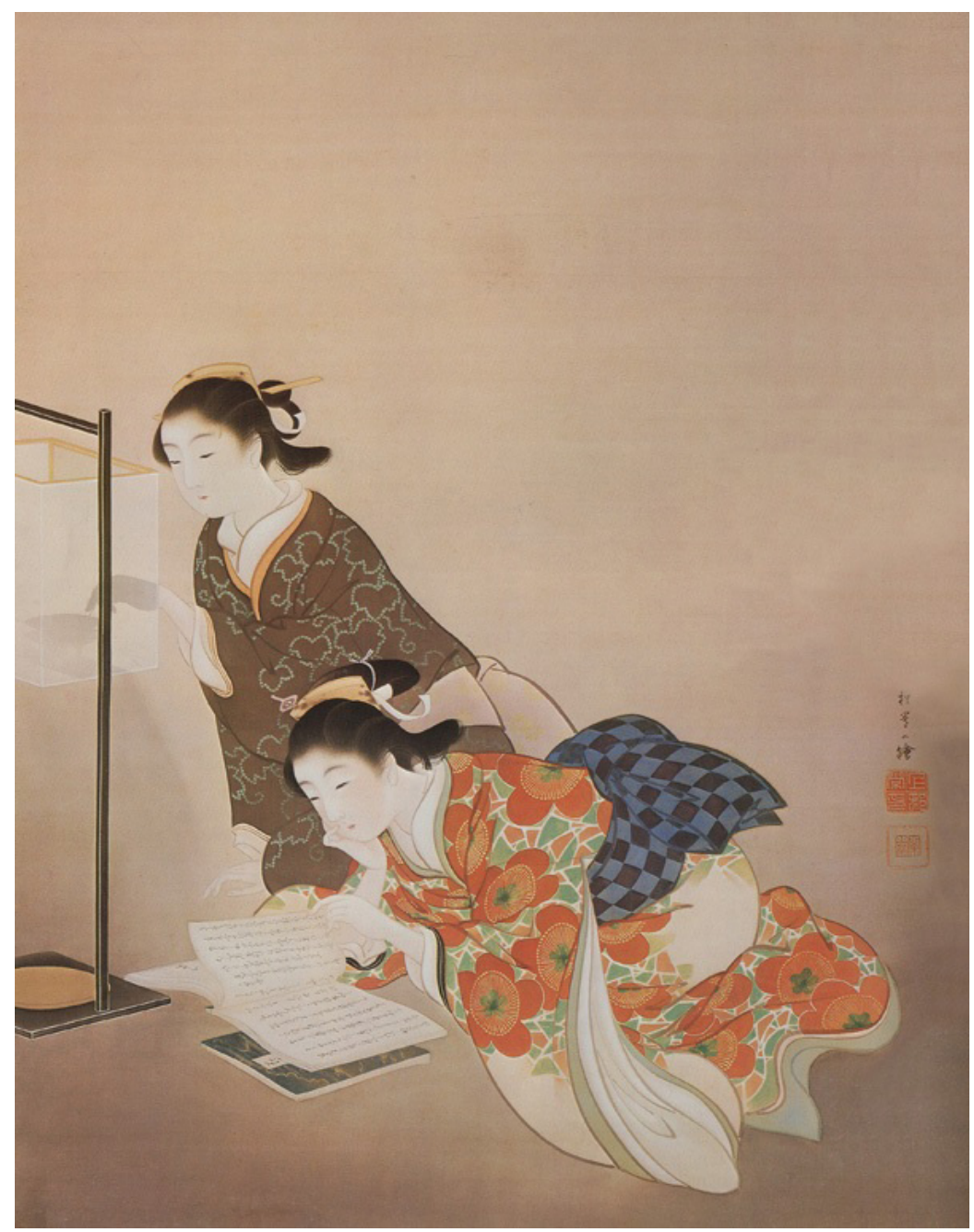

Fig. 4. Uemura Shōen. Larga velada (長夜, Nagayo), 1907.

Pintura sobre seda en rollo vertical, 138 x $99 \mathrm{~cm}$. Colección privada.

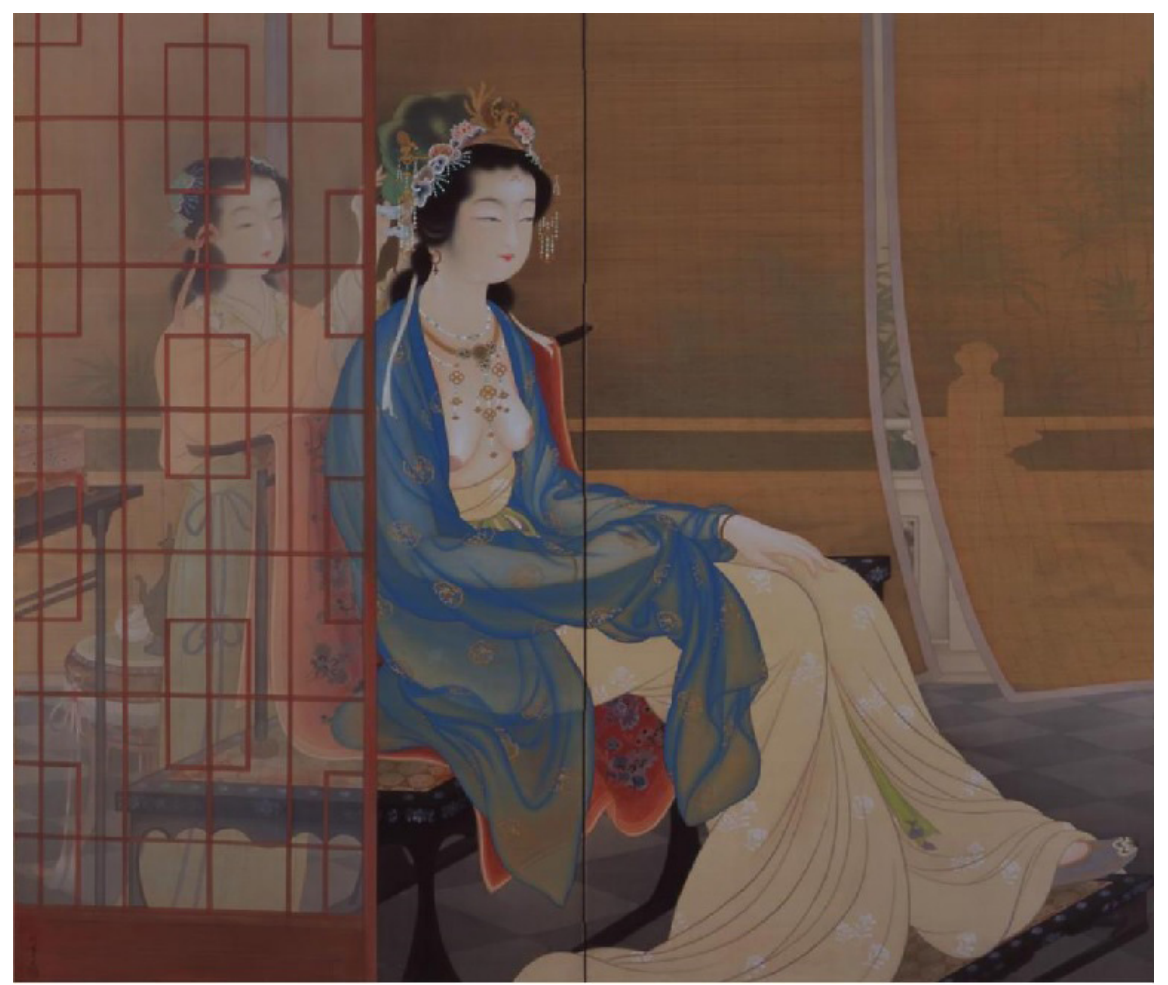

Fig. 5. Uemura Shōen. Amapola (Yang Guifei) (楊貴妃, Yokihi), 1922.

Pintura sobre seda en dos rollos verticales, 161 x $89 \mathrm{~cm}$ (cada uno). Shohaku Art Museum. 


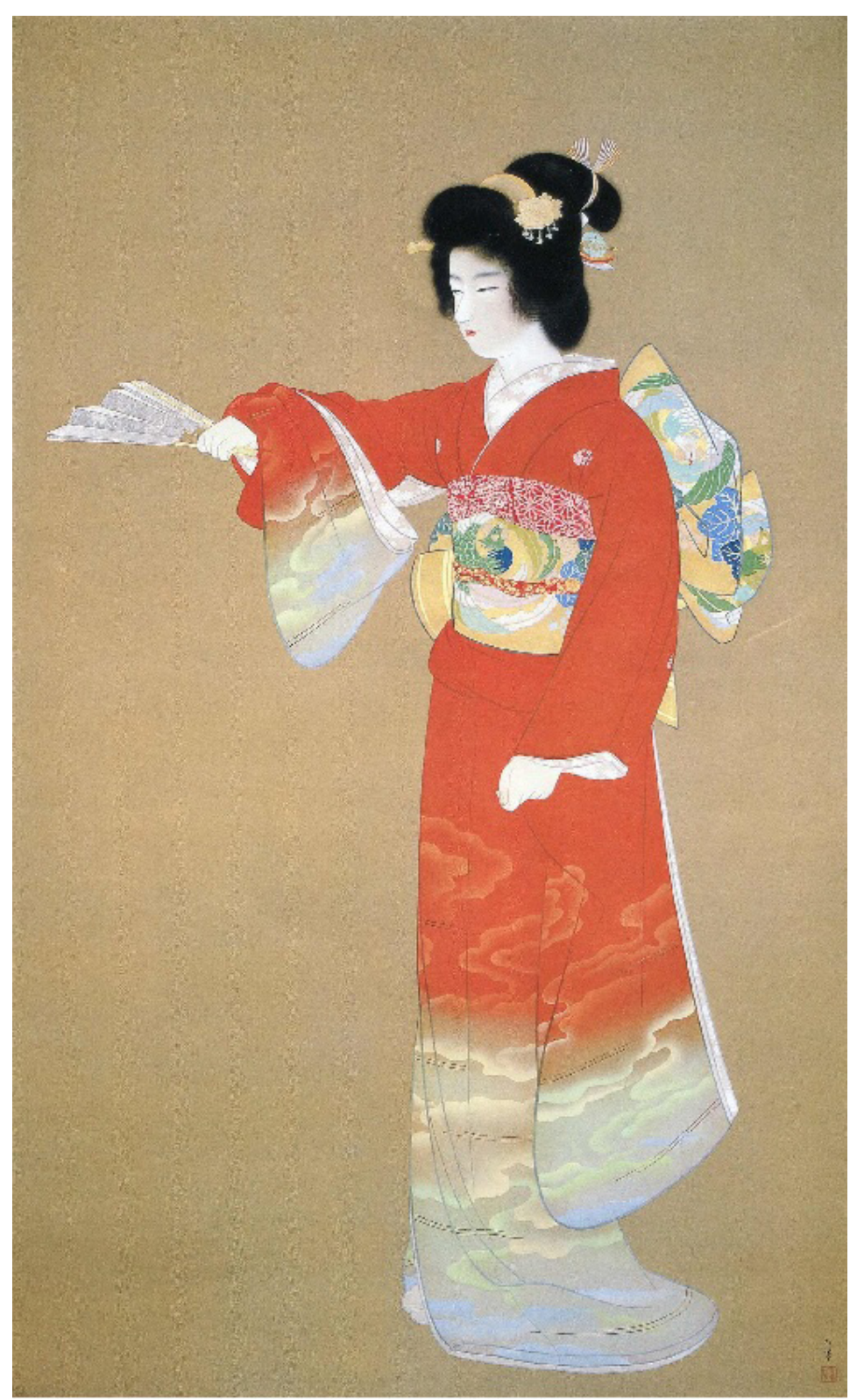

Fig. 6. Uemura Shōen. Danza de apertura (序の舞, Jo no mai), 1936.

Pintura sobre seda en rollo vertical, 233 x 141,3 cm. Propiedad cultural importante de Tokyo University of Arts.

Tras la muerte en 1934 de su madre, a la que estaba profundamente ligada, Shōen realizó numerosas declaraciones en torno a ella que la retratan como su principal fuente de inspiración, de empoderamiento y de confianza en sí misma. Así, en sus memorias, dejó escritas las siguientes palabras: "Estoy en deuda con mi madre no solo porque ella fue quien me dio la vida, sino porque también se la dio a mi propio arte." 19 Asimismo, realizó varias obras en su honor entre las que destaca Crepúsculo (夕暮れ, Yūgure) [fig. 7] de 1941.

En su última década de vida, Shōen fue ampliamente reconocida tanto por el público como por la administración. De esta manera, en el año 1941 se convirtió en miembro permanente de la Oficina Imperial de Artes y, en 1944, del Consejo Imperial de Artes. Un año antes de su muerte, en 1948, le fue otorgada la Orden al Mérito Cultural de Japón (文化勲章 Bunka kunshō) y se convirtió con ello en la primera mujer en recibirla desde el establecimiento de este reconocimiento en $1937^{20}$. En el año 1949 enfermó de cáncer de pulmón lo que la obligó a permanecer en reposo. Ella, que siempre había antepuesto su arte a su propia salud, mencionaba cuando agonizaba: "Tengo muchas cosas todavía por pintar. Cuando me recupere no pintaré ya para nadie. Únicamente me dedicaré a pintar con el fin de ganar un lugar en la historia". El día 27 de agosto de 1949 falleció en la ciudad de Nara, donde se había trasladado junto a su hijo y la familia de este durante el desarrollo de la guerra del Pacífico ${ }^{21}$.

\footnotetext{
Uemura, S. (2010): 135 (trad. autora).

20 Yamada, N. / Merrit, H. (1993): 16.

21 Ibidem.
} 


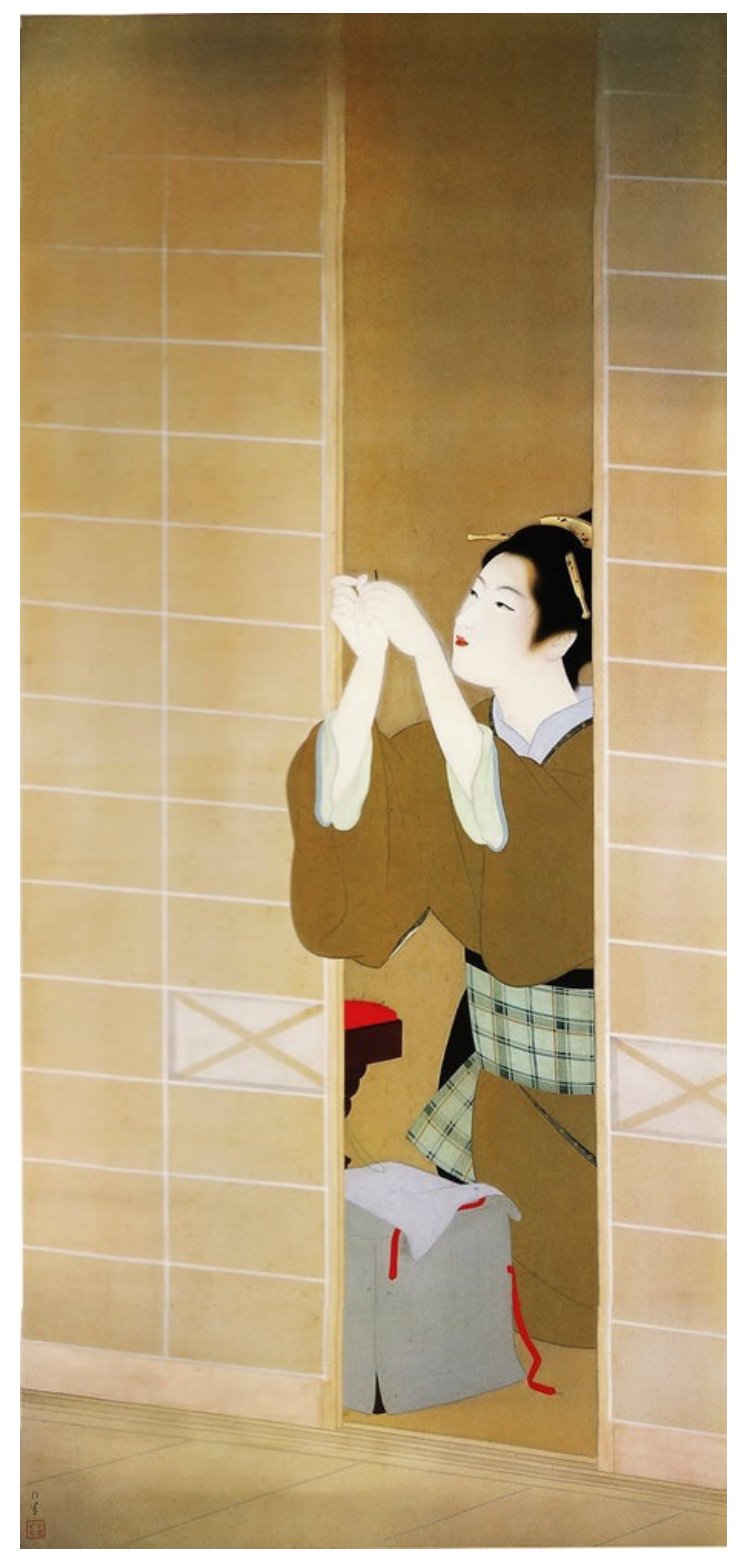

Fig. 7. Uemura Shōen. Crepúsculo (夕暮れ, Yūgure), 1941.

Pintura sobre seda en rollo vertical, 213 x $99 \mathrm{~cm}$. Ohki High School, Kioto.

\section{La llama: un estudio}

\subsection{Buscando la inspiración en el nō: Aoi no Ue}

Una vez que se ha presentado brevemente la vida de la artista, resulta imprescindible elaborar un enfoque que acerque a Shōen, mujer y artista, por medio de la obra prometida, La llama. La historia del personaje que aquí se representa está inspirada en una canción de teatro $n \bar{o}$, uno de los tres tipos de teatro japonés más famosos. Shōen, que en los años previos a la elaboración de esta pintura había comenzado a asistir a clases de este tipo de recitaciones, conocidas en japonés como yōkyoku ${ }^{22}$, optó por incluir en su pintura una de las actuaciones de su maestro Kongō Iwao (18861952) ${ }^{23}$. Esto coincide, tal y como he mencionado anteriormente, con un momento complicado en la carrera de Shōen, pues tenía ciertos problemas a la hora de representar las distintas expresiones humanas. Precisamente fueron este tipo de canciones yōkyoku las que supusieron una gran ayuda para ella ${ }^{24}$.

22 VV.AA. (1972): vol. 20: 70; yōkyoku (謡曲), parte narrativa del teatro $n \bar{o}$ que se refiere a la sección vocal de la música asociada a este tipo de teatro clásico. En general, es cantado por el coro y no por los actores y consiste en referencias a los textos clásicos del budismo. También alude a la acción de cantar estas partes integrales.

23 VV.AA. (1993): vol. 4: 270; Kongō Iwao (金綱嚴) fue la cuarta generación de la Escuela Kongō de maestros del nō. Esta escuela era una de las cinco escuelas shite-kata de actores profesionales de teatro nō. El nombre de esta escuela deriva de Ukyō Ujiyasu (1872-1936). Kongō Iwao de Kioto llegó a ser la cabeza de la escuela y en 1982, su hijo Iwao II fue el vigésimo quinto director de esta escuela.

24 Morioka M. (1996): 138. 
Aoi no Ue, la canción de la que bebe La llama, se inspira en la época Heian (794-1185), concretamente en uno de los episodios del Cuento de Genji $i^{25}$, la obra culmen de la literatura japonesa. En esta narración, escrita por el dramaturgo Zeami ${ }^{26}$ en el siglo XIV, Aoi no Ue, la esposa formal del protagonista, el príncipe Genji ${ }^{27}$, es poseída por el fantasma vengativo de la dama Rokujō no Miyasudokoro, amante de Genji y viuda del príncipe Zembo. A pesar de que esta dama gozaba de una gran reputación y sofisticación propia de una noble, pierde la atención y el favor que recibía de su amado Genji. De esta manera, con motivo de la celebración del festival del río Kamo en Kioto, donde coincide con Aoi no Ue, Rokujō se presenta ante el carruaje de la dama Aoi transformada en un espíritu vengativo y la golpea con el objetivo de arrebatarle su alma ${ }^{28}$. Ante esta situación, la familia de la dama Aoi pide ayuda a un monje que comienza a recitar una serie de plegarias. Es así como, aunque los celos que habitaban en el corazón de la dama Rokujō se habían materializado en una especie de ogro o demonio femenino, finalmente los rezos surten efecto y Rokujō vuelve en sí y se calma, alcanzando de este modo el nirvana o la iluminación budista ${ }^{29}$.

Aunque esta obra es un eje de vital importancia para la elaboración de esta pintura, resulta fundamental recalcar que lo que realmente Shōen recoge de esta canción en su trabajo es la emoción, ese sentimiento supuestamente femenino de los celos. Así, La llama no puede considerarse como una simple "pictorialización" de la dama Rokujō no Miyasudokoro sino la representación de la venganza de una mujer. A pesar de que, tal y como se ha mencionado, la leyenda está inspirada en la novela del periodo Heian, toma elementos de otros momentos de la historia japonesa, como el periodo Momoyama (1568-1603) o la más reciente era Taishō (1912-1926) ${ }^{30}$.

\subsection{El espíritu vivo de Rokujō}

Una vez se ha analizado el trasfondo del personaje de La llama, es necesario incidir en la composición y la figura que protagonizan esta extraordinaria obra de Shōen. Tal y como se ha comentado en el punto anterior, Rokujō se presenta como un espíritu vengativo. Este aspecto, que resulta en cierta medida extraño dentro de las representaciones occidentales, es sin duda bastante común en el universo japonés en el que numerosas manifestaciones artísticas, como es el caso de La llama, beben y maduran gracias al mundo fantástico ${ }^{31}$. Así, los personajes y fenómenos que pertenecen a lo sobrenatural invaden constantemente el mundo humano. De entre la gran variedad de criaturas sobrenaturales que pueden encontrase en el imaginario nipón, como los yōkai, oni, bakemono, etc. el espíritu que aquí aparece como Rokujō podría ser considerado un onryō, es decir, un fantasma, generalmente femenino, que regresa del más allá buscando venganza puesto que son almas motivadas por algún tipo de pasión, en este caso, los $\operatorname{celos}^{32}$. No obstante, precisamente gracias al estudio de la canción yōkyoku Aoi no Ue, se puede afirmar que Rokujō no proviene del más allá puesto que es una mujer viva, que está poseída pero que no ha fallecido, por lo que se debe abandonar la idea de que esta figura se corresponda con un onryō. Se trata, pues, de un ikidama, ikiryō o ikisudama [生き霊], cuya traducción literal al castellano no es otra que la de "espíritu vivo", y que engloba aquellos espíritus maléficos de una persona que se encuentra poseída por una fuerte pasión. De esta manera, seres como Rokujō no tienen por qué estar muertos para ocasionar daños a su víctima, sino que se transforman en vida durante los instantes que dura su venganza ${ }^{33}$. Uemura Shōen tenía clara la naturaleza de esta figura y así lo demuestra en sus memorias:

La llama es, de entre todas mis variadas pinturas, las más extrañamente hermosa. [...] Brotó en mi este propósito y es que elaboré una expresión que ardía como las llamas. En la canción yōkyoku Aoi no Ue, aparece el espíritu vivo de Rokujō no Miyasudokoro [...] En un principio, titulé esta obra como Ikidama, pero como este es un término demasiado amplio, pensé cuidadosamente cuál podría ser el título adecuado. Al final, hablé con el maestro Kongō Iwao que me dijo: "Ikidama también se lee como ikisudama. Pero, aunque le pongas ikisudama va a sonar igual... es preferible que la titules La llama. Me dijo esto. Entonces, como el carácter de "llama" de alguna manera encajaba a la perfección con la forma de la pintura, me decidí por este título ${ }^{34}$.

\footnotetext{
VV.AA. (1993): vol. 7: 328-329; El Cuento de Genji（源氏物語, Genji monogatari) la obra maestra de la literatura japonesa, ha sido considerada como la primera gran novela escrita en todo el mundo. Fue elaborada a comienzos del siglo XI y, a pesar de que su autoría se ha atribuido tradicionalmente a la dama de la corte Murasaki Shikibu, no existen documentos que descarten la existencia de otros autores posteriores que también hayan contribuido a la creación del trabajo. Esta novela se encuentra dividida en dos partes: la primera de ellas, que abarca los primeros cuarenta y un capítulos, narra la vida y amoríos del Príncipe resplandeciente o Hikaru Genji; la segunda, de apenas diez capítulos, toma a Kaoru y su rival, el Príncipe Niou, nieto de Genji, como protagonistas principales.

26 Ibíd: vol. 8: 369; Zeami (世阿弥), conocido también con el nombre de Kanze Motokiyo, fue un actor, escritor y crítico que contribuyó al asentamiento del $n o \bar{c}$ como arte escénico clásico. Aunque es el supuesto autor de cerca de noventa obras, únicamente le han sido acreditadas veintiuna. Con respecto a su carrera profesional, Zeami entendía el arte como camino hacia la perfección humana, lo que ilustra mediante los conceptos de "flor" (hana), que alude a la frescura y emoción que transmite el actor a sus espectadores, y "belleza sutil" (yügen), que simboliza la elegancia y gracia del misterio inefable.

27 VV.AA. (1972): vol. 16: 609; Hikaru Genji (光源氏) es el protagonista del Genji monogatari. Fue el segundo hijo del emperador Kiritsubo. Debido a su gran belleza se le comenzó a llamar "Hikaru Genji”, el Príncipe resplandeciente. De niño perdió a su madre, motivo por el que tuvo una aventura amorosa con su madrastra que le recordaba a ella. Tras la muerte de su mujer Aoi contrae matrimonio con Murasaki.

28 Tanaka, K. (2018): 56-58.

the-noh.com (2013).

Yoshimura, K. (2009): 29.

Requena Hidalgo, C. (2009): 11, 130

Ibid: : 47, 111.

Ibíd: 113.

Uemura, S. (2010): 100, 101 (traducción propia).
} 
En la cita anterior también se refleja el gran poder que ejerce el maestro Kongō en Shōen, tanto en la elaboración de esta pintura, por ser su actuación la fuente de inspiración, como en la elección del título de la obra ${ }^{35}$.

\subsection{Algún detalle técnico de La llama}

Shōen, que pretendía en un primer momento titular a esta obra como Ikidama $a^{36}$, era perfectamente consciente de la naturaleza sobrenatural de Rokujō y decidió plasmar estas características en su obra a partir de diversas estrategias como es el empleo de tonalidades grisáceas que componen el fondo. Por otro lado, detalles como la ausencia de pies de la figura [fig. 8], así como los dientes afilados que asoman de su boca reproducen el rencor de este personaje. Otro aspecto que podría pasar más desapercibido es el estampado del kimono [fig. 9]. En él, la flor de fuji o glicinia, una clara alegoría al verano japonés, se intercala entre la tela de araña, lo cual es una metáfora de la historia en la que se inspira la pintura: la araña que se corresponde con Rokujō atrapa a su presa, la flor de glicinia, que representa a la dama Aoi no $\mathrm{Ue}^{37}$.

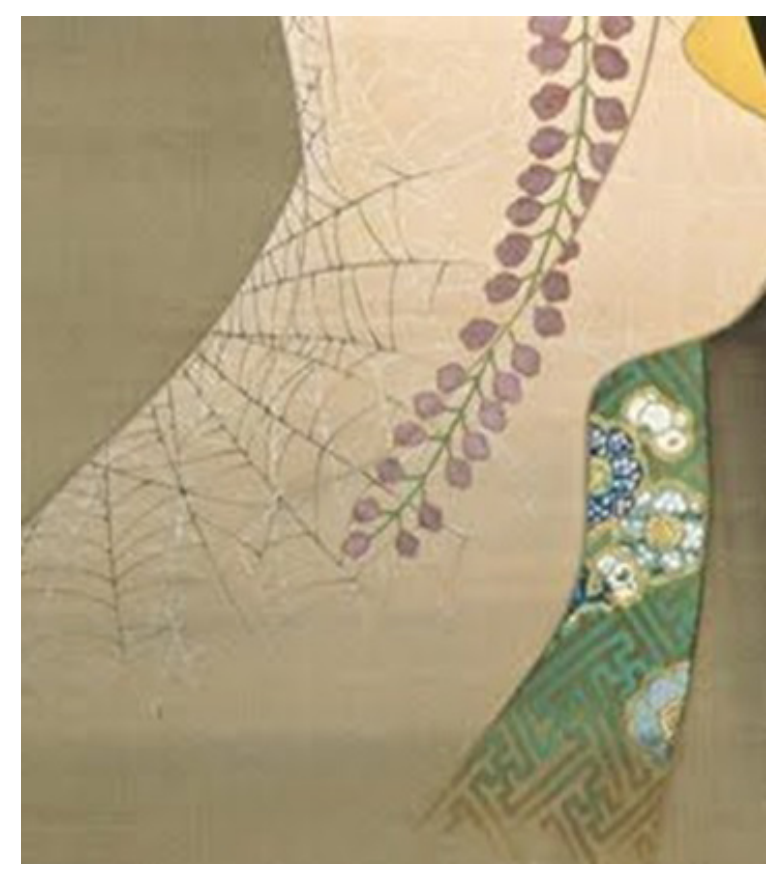

Fig. 8. Detalle de los pies de la figura de La llama.

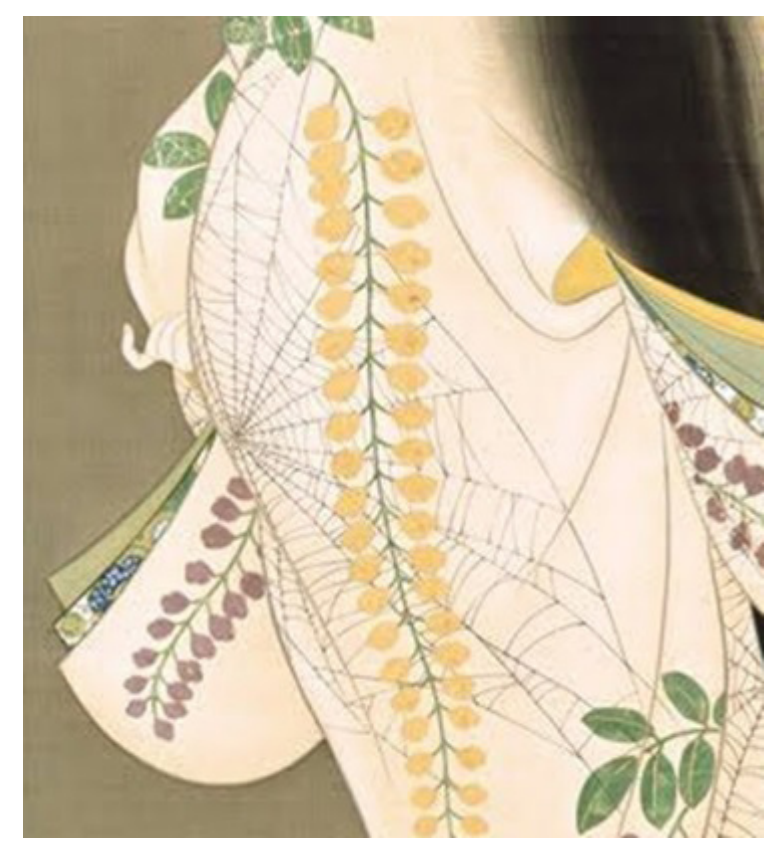

Fig. 9. Detalle del estampado de quimono de La llama.

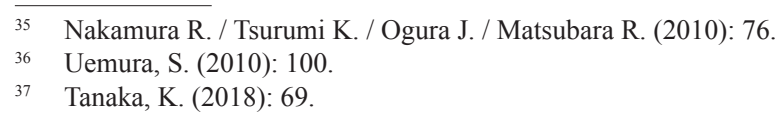


Por último, en cuanto a la parte más técnica de la obra, es imprescindible incidir brevemente en la mirada de la figura [fig. 10]. A pesar de que resulta difícil apreciar este detalle en la imagen, los ojos de este espíritu toman una tonalidad dorada que nos permite entender y empatizar con varias de las emociones que reproduce este personaje. Asimismo, la mirada de la figura recuerda a la máscara nō Hannya, que se emplea precisamente en la representación teatral de Aoi no Ue y muestra un sentimiento de ira y rabia ${ }^{38}$, por lo que el brillo de los ojos podría ser una de las consecuencias de los celos y la furia de Rokujō. Sin embargo, también se asimila este matiz dorado a las lágrimas que caen por sus mejillas ${ }^{39}$. Tal y como la propia artista narra en sus memorias, tuvo ciertas dificultades para elaborar esta expresión, por lo que de nuevo pidió consejo a su maestro de yōkyoku, Kongō Iwao. Shōen comenta en sus memorias la siguiente enseñanza que recibe: "En los rostros de las bellezas del $n \bar{o}$, se unta pintura dorada en el blanco del ojo [...] Así, cada vez que resplandece el dorado, aparece un brillo y un destello peculiar. Pero es que también se aprecia una expresión donde brotan las lágrimas"

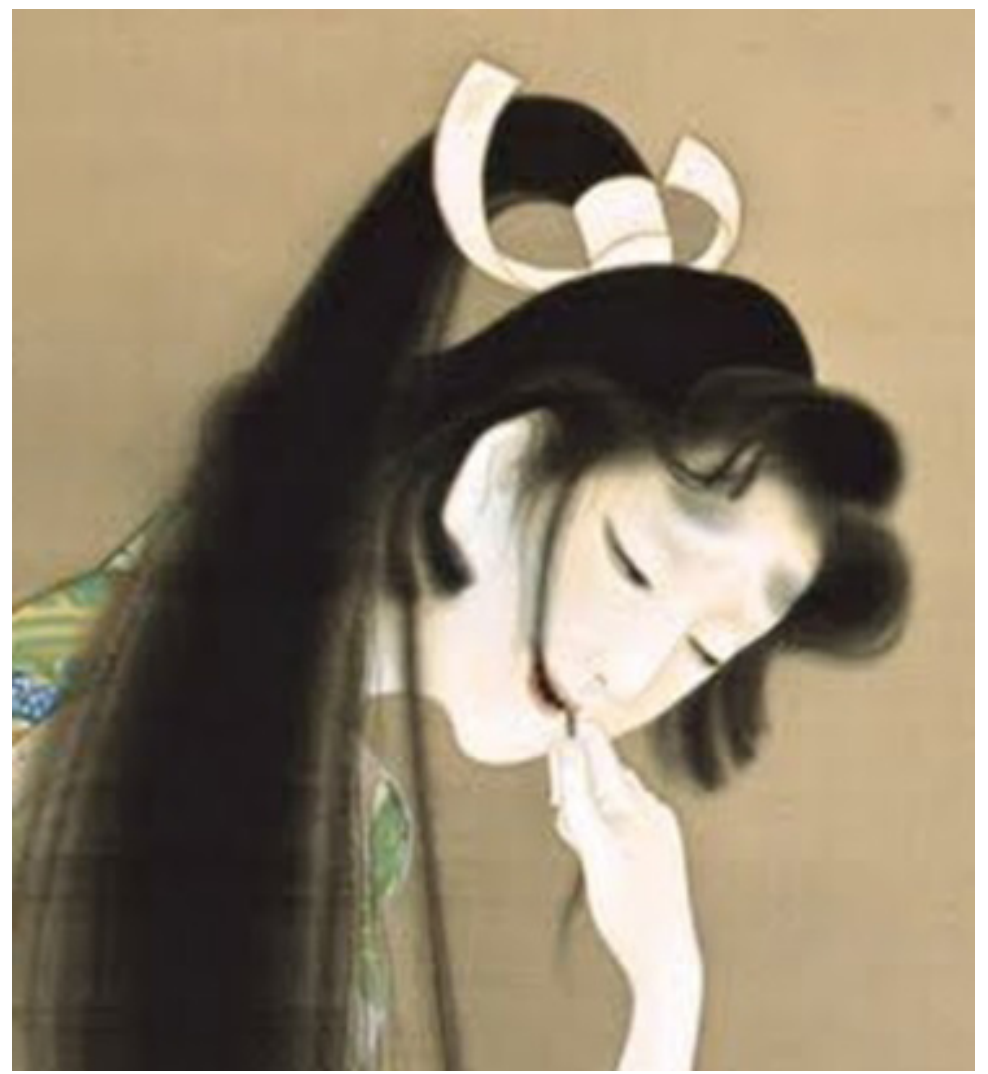

Fig. 10. Detalle de la mirada de la figura de La llama.

Siguiendo estas sugerencias, Shōen decidió pintar por el reverso de la seda con pintura dorada y con ello logra encumbrar esta belleza como el espíritu vivo y vengativo que es, convirtiendo las lágrimas y el dolor de Rokujōen una muestra de la falsedad de Genji, su antiguo amante.

\subsection{La verdadera venganza de Uemura Shōen}

Una vez analizada esta pintura desde un punto de vista iconográfico y técnico, resulta necesario elaborar un estudio en su contexto, es decir, incidiendo en el significado real y sincero que Shōen pretende mostrar en esta representación. De este modo, aquí se aportará una relectura de La llama que se desvincula de las declaraciones de críticos e historiadores que han malentendido esta figura como un simple arquetipo de la arpía malvada, asimilando a la vengativa Rokujō, una mujer celosa ante las infidelidades de su amante, con Shōen y su vida privada. Si bien es cierto que pueden establecerse ciertos paralelismos entre ambas mujeres, sería un grave error quedarse en un símil tan superficial. Debido a que existen numerosas teorías y especulaciones sobre las inspiraciones que recibe esta obra $^{41}$, es necesario recurrir a la voz de la propia pintora por medio de las declaraciones que realiza en su diario personal a fin de evitar caer en estos estereotipos patriarcales sobre la feminidad o el amor romántico que han sido creados en torno a esta figura

Tal y como se acaba de mencionar, esta obra ha sido incomprendida en numerosas ocasiones por la asimilación de la figura con un fantasma celoso ${ }^{42}$. Es así como grandes historiadoras del arte como Morioka Michiyo con la que

\footnotetext{
Cabañas Moreno, Pilar (2003): 111, 112.

9 Ibid.: 68.

Uemura, S. (2010): 160 (traducción propia).

41 Tanaka, K. (2018): 60.

42 Ibídem.
} 
se trabaja en este estudio, afirman que La llama es un trabajo inusual fruto del dolor ocasionado por la muerte del maestro Shōnen en enero de $1918^{43}$. Aunque en general las críticas e investigaciones japonesas no vinculan esta pintura con la desaparición del maestro que supuestamente Shōen no pudo tener, sí que pueden encontrarse estudios que inciden de nuevo en el estado emocional de Shōen a la hora de elaborar La llama. Así, Maruki Tsubasa afirma que la artista, atormentada por la pérdida de su amor de juventud, decide plasmar su situación sentimental en esta obra ${ }^{44}$.

El imaginario artístico siempre ha intentado adoctrinar a las mujeres sobre los roles que pueden llevar a cabo, por lo que de algún modo, puede decirse que el arte establece el límite entre la feminidad ideal y la desviada, reforzando así los códigos patriarcales ${ }^{45}$. Sin embargo y volviendo de nuevo a la obra que aquí se trata, aunque es cierto el hecho de que la figura de Rokujō representa a un ente celoso, esto no niega lo que realmente es: una mujer que siente y expone sus sentimientos y, en este caso, se venga de aquellos que la maltratan y hacen daño. De esta manera, no se puede establecer una comparación tan trivial como que Shōen podría estar vengándose por medio de esta pintura de algún amante, como el padre de su hijo, su primer maestro Suzuki Shōnen, que no reconoció a su hijo como tal hasta que este cumplió catorce años.

Si bien es innegable que existe la venganza como uno de los componentes esenciales de esta obra, esta se dirige a todos esos artistas y críticos del arte que tachaban tanto a Shōen como a su arte de falta de originalidad y de un excesivo gusto por la tradición clásica japonesa. Por ejemplo, el historiador del arte Ueda Juzō (1886-1973) realiza una crítica negativa de Cesto de Flores [fig. 11], una pintura de Shōen elaborada en el año 1915, y argumenta que las figuras de esta artista carecen de cuerpo y de espíritu ${ }^{46}$. Por otro lado, el director encargado de la columna de crítica artística de uno de los principales periódicos de la ciudad de Kioto, Kyoto Hinode-shinbun, declara en 1909 lo siguiente: "Las obras de Shōen son bellas y lo son porque nos permiten contemplar las figuras de Kioto. Sin embargo, por debajo de la piel de esas pinturas, no corre sangre" ${ }^{47}$. Estos reproches que la artista recibe no son más que una muestra de las tendencias artísticas de la época que reclaman un nuevo bijinga que se aleje de las influencias del ukiyo-e y de las tradiciones del periodo Edo, en busca de una imagen novedosa de la mujer de los tiempos modernos ${ }^{48}$.

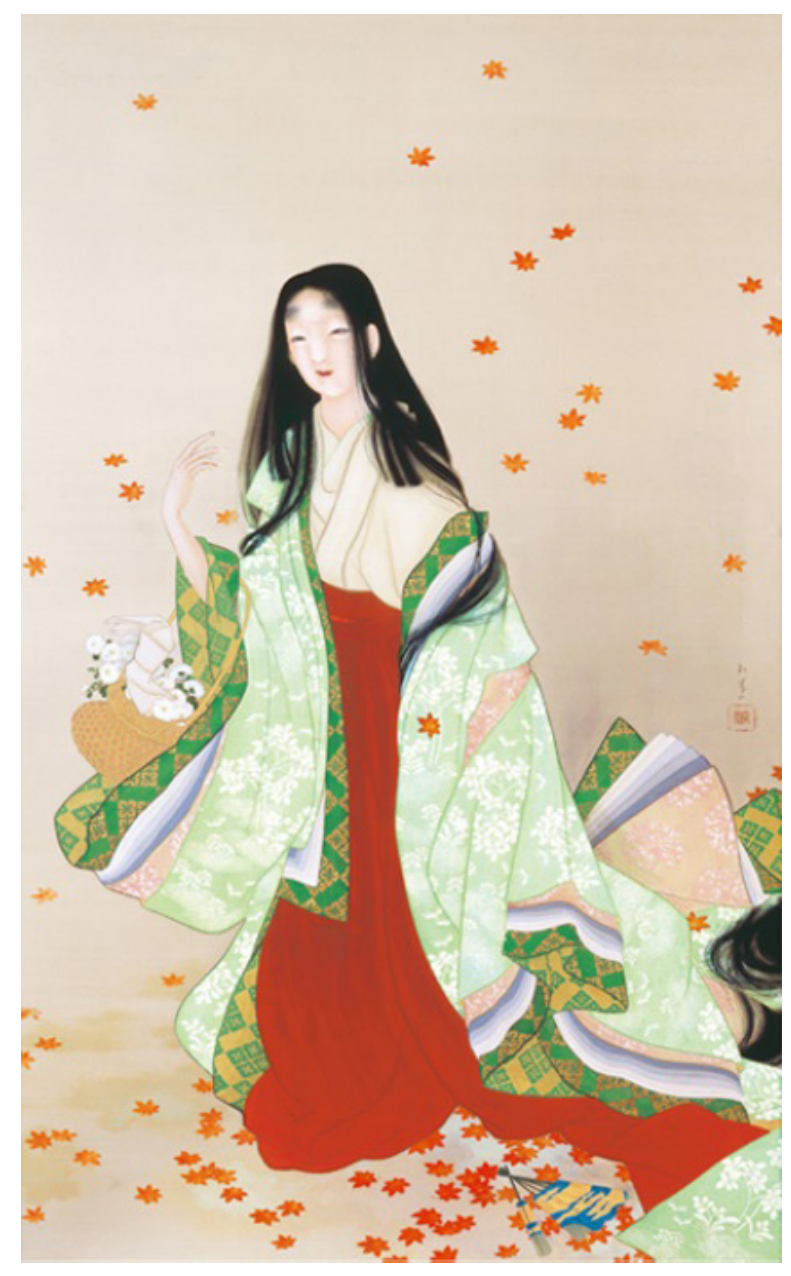

Fig. 11. Uemura Shōen. Cesto de flores (花がたみ, Hana gatami), 1915.

Pintura sobre seda en rollo vertical, 208 x 127 cm. Shōhaku Art Museum, Nara.

\footnotetext{
Morioka, M. (1990): 76, 77.

Maruki, T. (2012): 226.

Mayayo, P. (2003): 138.

Tanaka, K. (2007): 34.

Ibid.: 35 .

Ibid: 32 .
} 
La llama se erige por tanto como un punto de inflexión en la obra de Shōen: se entiende como una respuesta hacia todos aquellos que critican su arte por estar supuestamente desfasado y podría considerarse de algún modo como un desafío de la artista hacia todos ellos. De esta manera, Shōen rompe con la línea que seguían sus obras anteriores de bellezas del Japón tradicional, para dar luz así a esta pintura de extraña belleza. Es a partir de este momento cuando sus figuras dejan de ser mujeres bellas y dulces para ser más pasionales y sentimentales, con el objetivo de crear una reacción en el espectador ${ }^{49}$.

No obstante, esto no implica que Shōen terminara por asumir los nuevos movimientos artísticos y seguir aquello que sus críticos le exigían sino que la pintora se venga de todo aquello que le disgusta en el arte y logra innovar y representar mujeres dignas en una dirección completamente distinta a la de sus contemporáneos, es decir, sin caer en la sensualidad excesiva de la figura femenina y exponiendo al máximo las emociones y los sentimientos más profundos tanto del personaje como de la propia artista. Para Shōen, el hecho de seguir los consejos de los críticos y a las corrientes artísticas mayoritarias suponía en cierta medida una deslealtad para consigo misma. La artista realiza ciertas declaraciones que explican por qué siente reticencias hacia lo considerado moderno por las masas: “Acatar solo los nuevos estilos no eleva necesariamente la valoración que se tiene de uno mismo. Las nuevas críticas traicionan los deseos del yo más puro y también es cierto que se burlan del mismo"

En esta obra, Shōen aclara que la clave para sobresalir en el arte no es precisamente seguir a ciegas, sin criterio alguno, aquello a lo que los expertos incitan, sino que debe realizarse lo que real y sinceramente motiva al propio artista. De este modo, Shōen, que siempre se inspiró en la tradición japonesa que bebe desde pequeña gracias a su madre, se defiende de las críticas que la tachan de artista anticuada:

Yo, siguiendo mis propios gustos, he ido elaborando pinturas fūzokuga ${ }^{51}$ de mujeres del pasado. Hay gente que dice que estoy demasiado influida por las viejas costumbres. Pero el que yo intente mirar hacia el pasado no implica que me guste especialmente, sino que al hacer esto creo que existe una mayor profundidad en las expresiones. Ahora, lo de ahora, cualquiera puede verlo y conocerlo ${ }^{52}$.

Con estas palabras, se observa cómo realmente Shōen tiene una fuerte convicción de lo que hace y de cuál es su cometido en el mundo del arte: dar forma en sus obras a una serie de sentimientos que representan emociones profundas. Con respecto a esta pintura, Shōen, que es siempre fiel a sí misma, reproduce su rabia y dolor ante las críticas utilizando como vía de escape la figura de Rokujo ${ }^{53}$. De este modo, se pueden establecer ciertas similitudes entre ambas mujeres que se alejan completamente del estereotipo de la mujer celosa por un amor romántico enfermizo. Representa el momento en el que Rokujō se transforma en un espíritu vengativo y sale de su cuerpo con el objetivo de mostrar sus sentimientos más sinceros y reales, algo que sin duda le era negado a las mujeres nobles del periodo Heian. Como la propia Rokujō afirma en la canción yōkyoku:

La gloria de ayer es el sueño de hoy

Qué estúpida he sido al no darme cuenta

Aparte de mi depresión, el rencor hacia ella me causa más sufrimiento

Y no puedo controlar más a mi corazón ${ }^{54}$.

Es de esta manera cómo la dama Rokujō da salida a su rencor y sus celos exponiendo sus sentimientos, contando qué es lo que le sucede y respondiendo ante ello. Shōen, por su parte, también se sincera y es capaz de superar su agonía artística sacando a la luz todo aquello que siente por medio de sus pinturas ${ }^{55}$. Como ella misma afirma: "Y es que en aquel momento [la elaboración de La llama], mi arte pasaba por una depresión, y, el sufrimiento que no podía superar de ningún modo se inmortalizó en esta pintura. Es posible que con ello superara todos mis propósitos" ${ }^{96}$.

Tanto en la declaración anterior de Rokujō como en esta de Shōen, son comunes el sufrimiento provocado y la depresión por la que caminan ambas mujeres. Sin embargo, tanto una como la otra logran sobreponerse y alcanzar de algún modo el aclamado nirvana siendo fieles a ellas mismas en todo momento. Así, escuchando las palabras de Shōen, se puede entender su arte bajo otra perspectiva, bajo otra mirada más inclusiva que no se limita a comparaciones superficiales y que pone fin a una errónea lectura de la figura como arpía malvada que adoctrina a las mujeres sobre los roles que pueden representar y de los que deben huir. Resulta esencial prestar atención a la voz de esta artista que explica de primera mano las verdaderas motivaciones que la incitan a continuar en el mundo del

\footnotetext{
9 Yoshimura, K. (2009): 29.

Uemura, S. (2010): 204 (trad. autora) ukiyo-e.

52 Uemura, S. (2010): 258 (trad. autora).

53 Tanaka, K. (2018): 67.

54 the-noh.com (2013).

55 Tanaka, K. (2018): 67.

56 Uemura, S. (2010): 101 (trad. autora).
}

51 VV.AA. (1993): vol. 2: 377; füzokuga (風俗画) es un tipo de pintura de género que muestra escenas de la vida cotidiana: mercados, hogares, interiores, fiestas, escenas de la calle, etc. Comenzó el tercer cuarto del siglo XVI y predominó hasta el final del XVII. Estas pinturas reflejan tanto la consciencia de los quehaceres diarios, así como los placeres del mundo. Surgió de entre las tradiciones japonesas como las pinturas yamato-e de lugares famosos, las pinturas estacionales o la representación de eventos mensuales. De él arrancan las representaciones de mujeres bellas del 
arte. A pesar de que ella misma admite que ha pasado por diversas complicaciones provocadas por el hecho de ser mujer en el arte ${ }^{57}$, un mundo monopolizado por artistas masculinos, y que siempre supo dotar a sus representaciones de fortaleza y fidelidad hacia ella misma. Tal y como la propia Shōen admite, quería representar a mujeres fuertes ${ }^{58}$. Con La llama no busca meramente transformar en pintura una leyenda sino mostrar el poderío y la sinceridad de las mujeres y, también, incidir en sus propios sentimientos y preocupaciones que han sido ignorados. Mediante la elaboración de esta obra, Shōen pudo encontrarse a sí misma y también construir su camino en la pintura, separado de lo estipulado y fuera de prejuicios. Ella misma se abre por completo en su diario y nos transmite estas duras palabras:

En la vida te encuentras con lluvia y viento, y el barco se desvanece como si se hundiera. De igual forma yo he pasado por diversos momentos de penurias. Unas veces porque alcanzaba los límites artísticos; otras, por preocupaciones de la vida. En muchas ocasiones llegué a pensar de verdad que la muerte sería mucho mejor que la vida que estaba viviendo si seguía lamentándome así [...] Cuando recuerdo esto ahora, se acumulan numerosos lamentos de cuando yo era más joven, pero se desvanecen por completo al haber sido purificados artísticamente ${ }^{59}$.

De esta manera se comprueba una vez más cómo la artista se aleja de clichés y falsos mitos sobre la representación femenina. Para ello, Shōen emplea la pintura como un lenguaje reivindicativo en el que expresa sus sentimientos y creencias, su propia mirada, con la que es capaz de desarticular roles y estereotipos impuestos por el imaginario patriarcal y desarrollar simultáneamente una nueva visión artística que mire diferente y que, por lo tanto, cree un universo diferente.

\section{Conclusiones}

Tal y como se ha querido demostrar en este breve artículo, aquí se ha presentado la obra La llama y a su creadora, Uemura Shōen, desde una investigación que incide tanto en la vida personal y declaraciones de la pintora como en un estudio más contextual, analizándolo desde un enfoque que se adentra de lleno en las emociones, sentimientos y propósitos que la pintora inculca a cada cuadro que elabora. Así, La llama, su obra más célebre puede entenderse como una completa declaración de intenciones donde a través de una técnica y composición precisas, la artista demuestra su valía ante los críticos que pretendían despreciar su arte.

A través de un acercamiento biográfico a la pintora, así como una revisión de esta figura empleando como recurso principal las declaraciones personales de Shōen recogidas en Seibishō, se ha podido elaborar una nueva lectura de La llama que se aleja de las críticas superficiales que meramente vinculan esta obra con la vida privada de la artista. Así, Seibishō, las memorias de Uemura Shōen, se erigen como uno de los puntos fuertes de esta investigación, pues las notas y apuntes escritos por la pintora suponen un material imprescindible que permite realizar este análisis bajo otra mirada mientras que, simultáneamente, facilita dar voz a la propia artista. De este modo, con este artículo se ha rescatado a una figura tan relevante para la pintura japonesa del siglo XX como es Uemura Shōen en la historiografía construida desde Occidente, dominada por el heteropatriarcado y la jerarquía sexista que siguen imponiéndose en el arte y relaciona la feminidad y el trabajo artístico de las mujeres con una baja calidad. Considero de relevancia este estudio pues, aunque son muchos los investigadores e investigadoras del arte que recientemente han comenzado a incluir esta perspectiva de género en sus trabajos y sitúan a las mujeres como protagonistas de la Historia del Arte es necesario incidir y estimular estas revisiones que aportan nuevas lecturas e ideas a la vez que cuestionan el canon tradicional, tal y como se ha demostrado aquí ${ }^{60}$.

En esta línea, y basándonos en los propios escritos y obras de Uemura Shōen que se han trabajado aquí, queda claro que, en contra de lo que afirmaban sus detractores, ella fue una artista que se abrió por completo al espectador en cada una de sus obras y que no permitió que nada ni nadie cambiaran sus principios en lo que respectaba al arte. Shōen, que tal y como se ha comprobado dedica su vida al estudio de la pintura, es una de las grandes protagonistas de la Historia del Arte de Japón y su aportación no debe ser considerada menor a la de cualquier hombre artista, pues su gran devoción hacia la pintura es total en cada momento de su vida artística. Esto se refleja en declaraciones como la siguiente: "Cuando cojo el pincel entre mis manos es una sensación liberadora, que es la más placentera, la más noble, que se asemeja al gusto de los dioses" ${ }^{\prime}$.

Mediante el conocimiento de estos referentes y de la herencia de estas "madres" como Shōen, se pueden narrar nuevas historias de mujeres, en plural, que se alejen de un sujeto femenino universal, blanco y occidental. Es así

\footnotetext{
Ibid:: 99. Por ejemplo, Shōen narra en sus memorias el boicot que sufre una de sus obras, Kiyu la Cortesana, en su lugar de exposición, donde algún celoso de la obra de la artista decide manchar con tinta el rostro de la figura. Los propios directivos de la exposición no dan importancia al hecho de que se haya ensuciado esta obra de arte y no se haya respetado su lugar de exposición, y en lugar de pedir perdón a la artista, le exigen su restauración inmediata.

58 Fister, P. (1997): 3-4.

59 Uemura, S. (2010): 88-89 (trad. autora).

60 A pesar de que aún son pocos los estudios que aportan esta nueva mirada inclusiva, es importante destacar dentro del ámbito nacional la labor de la historiadora del arte Patricia Mayayo que en su estudio Arte en España (1939-2015): ideas, prácticas, políticas incluye una renovación historiográfica que recupera protagonistas que han sido expulsados del canon tradicional que fundamenta la Historia del Arte, como es el caso que aquí se trata, las mujeres artistas.

61 Uemura, S. (2010): 88-89 (traducción propia).
} 
como únicamente se puede empezar a vislumbrar una plena integración de las mujeres en el origen y desarrollo del arte universal.

\section{Bibliografía}

Cabañas Moreno, Pilar (2003): “Uemura Shōen en las Ramblas. Todavía un misterio”. En: Màteria. Revista Internacional d'Art. No. 3, pp. 109-114.

Fister, Patricia (1988): Japanese Women Artists 1600-1900. Lawrence: University of Kansas, Spencer Museum of Art.

Fister, Patricia (1997): "Feminine Perceptions in Japanese art of the Kinsei Era". En: Nichibunken Japan Review: bulletin of the International Research Center for Japanese Studies. Kioto: International Research Center for Japanese Studies, Vol. 8, pp. 3-21.

Hirota, Masaki (1999): "Notes on the 'process of creating women' in the Meiji Period”. En: Wakita Haruko / Bouchy, Anne / Ueno, Chizuko (eds.): Gender and Japanese History. Osaka: Osaka University Press, Vol. 2: The Subject and Expression/Work and Life, pp. 197-220.

Iwahori Yoko (1999): “Jogaku zasshi (The Women's Magazine) and the Construction of the Ideal Wife in the midMeiji Era”. En: Wakita Haruko / Bouchy, Anne / Ueno, Chizuko (eds.): Gender and Japanese History. Osaka: Osaka University Press, Vol. 2: The Subject and Expression/Work and Life, pp. 391-412.

Maruki Tsubasa (丸木翼) (2012): “Uemura Shōen ni okeru josei no risōzō” (「上村松園における女性の理想像」). En Bijutsukakenkyu (美術科研究). Osaka: Ōsaka Kyoiku University Repository, pp. 215-230.

Marzo, Jorge Luis y Mayayo, Patricia (2015): Arte en España (1939-2015): ideas, prácticas, politicas. Madrid: Cátedra.

Mayayo, Patricia (2003): Historias de mujeres, historias del arte. Madrid: Ensayos Arte Cátedra.

Morioka, Michiyo (1990): Changing Images of Women: Taishō-Period Paintings by Uemura Shōen (1875-1949), Itō Shōha (1877-1968) and Kajiwara Hisako (1896-1988). (tesis doctoral dirigida por Paul Berry y Glenn T. Webb). Division of Art History, University of Washington.

Morioka Michiyo (1996) "Uemura Shōen”. En Connant, Ellen P./ Rimer, J. Thomas / Owyoung, Stephen D. Nihonga. Transcending the Past-Japanese Style Painting 1868-1968. New York: Weatherhill \& The Saint Louis Art Museum.

Nakamura Reiko / Tsurumi Kaori / Ogura Jitsuko / Matsubara Ryūichi (中村麗子/鶴見香織/小倉実子/松原龍一) (2010): Uemura Shōen-ten (上村松園展). Tokyo / Kyoto: Nikkei Inc.

Requena Hidalgo, Cora (2009): El mundo fantástico en la literatura japonesa. Gijón: Satori.

Tanaka Keiko (田中圭子) (2007): Taishō-ki ni okeru Kyōto nihonga no josei hyōgen - kannōbi to riarizumu (大正期に おける京都日本画の女性表現-官能美とリアリズム). Tesis doctoral. Kioto: Graduate School of Core Ethics and Frontier Sciences, Ritsumeikan Daigaku.

Tanaka Keiko (田中圭子) (2018): Urameshii-e: Nihon bijutsu ni miru enkon no kyōen (『うらめしい絵：日本美術に 見る怨恨の競演』). Tokyo: Seibundō shinkōsha.

the-noh.com (2013): “Aoi no Ue” (葵の上). The-noh.com (the能ドットコム編集部). http://the-noh.com/en/plays/data/ program_006.html [consulta: 01/05/2020].

Yamada Nanako / Merrit, Helen (1993): “Uemura Shōen. Her Paintings of Beautiful Women”. En: Woman's Art Journal, Nueva Jersey, Old City Publishing, Vol. 13, pp. 12-16.

Yoshimura Keiko (吉村佳子) (2009) “Uemura Shōen Honoo ni miru fuji to kumo no su monyō” (上村松園「皕」に みる藤と蜘蛛の单文様). En: Fukushoku bigaku (『服飾美学』). Nishinomiya: Fukushoku bigaku-kai, pp. 19-34.

Uemura Shōen (上村松園) (2010): Seibishō. Seibishō sono go (青眉抄。青眉抄その後). Tokyo: Kyūryūdō.

VV.AA. (1990): A dictionary of Japanese Art Terms, Tokyo: Tokyo Bijutsu.

VV.AA. (1993): Kodansha Encyclopedia of Japan. Tokyo: Kodansha Ltd.

VV.AA. (1972): Nihongo Kokugo Daijiten, Tokyo: Shōgakkan.

\section{Fuentes de las imágenes}

Nakamura Reiko / Tsurumi Kaori / Ogura Jitsuko / Matsubara Ryūichi (2010): Uemura Shōen-ten. Tokyo / Kyoto: Nikkei Inc., pp. 33, 36, 55, 75, 77, 79, 137 y 147. 